\title{
Economic Competition and Racial/Ethnic Disparities in Sentencing: A Test of Economic Threat Perspective
}

\author{
Christopher D'Amato *, Bryan Holmes and Ben Feldmeyer
}

check for

updates

Citation: D'Amato, Christopher, Bryan Holmes, and Ben Feldmeyer. 2021. Economic Competition and Racial/Ethnic Disparities in Sentencing: A Test of Economic Threat Perspective. Social Sciences 10: 206. https://doi.org/10.3390/ socsci10060206

Academic Editors: Tina Freiburger and Kareem Jordan

Received: 28 April 2021

Accepted: 25 May 2021

Published: 1 June 2021

Publisher's Note: MDPI stays neutral with regard to jurisdictional claims in published maps and institutional affiliations.

Copyright: (c) 2021 by the authors. Licensee MDPI, Basel, Switzerland. This article is an open access article distributed under the terms and conditions of the Creative Commons Attribution (CC BY) license (https:// creativecommons.org/licenses/by/ $4.0 /)$.
School of Criminal Justice, University of Cincinnati, Cincinnati, OH 45220, USA; holmesbs@ucmail.uc.edu (B.H.); feldmebn@ucmail.uc.edu (B.F.)

* Correspondence: damatocj@ucmail.uc.edu

\begin{abstract}
Economic threat arguments within the broader racial/ethnic threat theory suggest that economic competition between minorities and Whites encourages the majority group to apply formal social controls on minorities to maintain their advantaged positions. Prior sentencing research has given limited attention to economic threat and has only done so using cross-sectional measures, which does not capture changing economic circumstances (a key element of racial/ethnic threat). The goal of this study is to provide a test of economic threat—and racial/ethnic threat more broadly—utilizing time variant measures. To achieve this goal, we use case-level data from the Minnesota Sentencing Guidelines Commission ( $N=122,666)$ and county-level data from the United States Census Bureau. Multilevel regression models reveal partial but limited support for economic threat. Specifically, counties with a growing portion of minorities living above the poverty line between 2000 and 2010 had larger minority disadvantages (in comparison to Whites) at incarceration. However, economic threat measures do not significantly contextualize minority-White sentence length differences, while the broader racial/ethnic threat measures do not significantly influence minority-White outcomes at the incarceration or sentencing length decision. The results suggest that economic threat may explain a small but limited portion of the racial disparities identified.
\end{abstract}

Keywords: economic threat; racial threat; racial disparities; ethnic disparities; sentencing

\section{Introduction}

Over the past several decades, research has consistently shown that racial/ethnic minority defendants are exposed to harsher sentencing outcomes than similarly situated White defendants (Spohn 2000; Ulmer and Parker 2020; Zatz 1987). Given these persistent disparities, researchers have been tasked with explaining why they exist (Mears et al. 2016). Although many potential explanations are feasible (see Mears et al. 2016), one theoretical explanation that has received considerable empirical attention is Blalock's (1967) racial threat theory. Racial (and ethnic) threat theory is a conflict perspective (Chambliss 1976) which argues that formal social controls, such as criminal justice sanctions, are used by the dominant group in society to control the behavior of groups who threaten their dominant status (e.g., racial/ethnic minorities; Blauner 1972; Liska 1992; Turk 1969). Thus, racial/ethnic threat theory argues that as minority groups grow in power, the majority group will increasingly use criminal justice sanctions (e.g., longer sentences) as a vehicle to "tame" minority populations advances (Blalock 1967; Blumer 1958; Feldmeyer and Cochran 2018).

To date, the research on racial/ethnic threat theory in the criminal justice system provides markedly mixed results at different criminal justice contact points such as police expenditures/size, arrest, and sentencing (Chamlin 1989; Kent and Jacobs 2004; Liska and Chamlin 1984). Notably, findings in the sentencing literature on racial/ethnic threat have been particularly mixed. For example, Johnson et al. (2008) found that judges are less likely to grant downward sentencing departures to minorities in districts with rising racial/ethnic populations (a finding in support of racial threat). However, other studies have found that 
percent of minority residents in a population is unrelated to racial differences in sentencing outcomes (Britt 2000; Kautt 2002). Moreover, others have found that racial/ethnic threat theory only applies to certain sentencing outcomes or situations (Feldmeyer and Ulmer 2011; Feldmeyer et al. 2015; Ulmer and Johnson 2004).

There are a few potential explanations for these varied findings in past research, one of which is that racial/ethnic threat studies often fail to fully test the theoretical tenets of Blalock's (1967) theory. Blalock (1967) differentiated between three distinct forms of threat: (1) political threat, (2) criminal threat, and (3) economic threat (Eitle et al. 2002). Political threat suggests that, in an attempt to maintain political power, the majority group will impose greater social controls on minority populations with growing political influence and power (e.g., growing shares of the voting block). Criminal threat predicts that the powerful group will impose increased levels of social control as minority groups appear to pose a greater crime risk, especially to Whites (e.g., higher levels of Black-on-White crime) (Blalock 1967; Eitle et al. 2002; Liska and Chamlin 1984). Economic threat-the focus of the current study-argues that competition between minorities and Whites for a finite number of economic resources (e.g., job opportunities) encourages the majority group to use formal social controls to maintain their privileged economic status (Blalock 1967; Feldmeyer and Cochran 2018). Under an economic threat framework, one would expect that areas with more economic competition between Whites and racial/ethnic minorities to have greater racial/ethnic disparity in criminal justice outcomes.

All forms of threat are important to examine but economic threat is particularly important for a few reasons. First, in comparison to the other types of threat described by Blalock (1967), economic threat has received the proverbial "short end of the stick" in terms of criminal justice scholarly attention. There is a sizable body of literature that has examined how potential crime threats (e.g., fear of crime, perceived crime risk) have been linked to greater support for punitiveness, especially toward minorities (see Chiricos et al. 1997, 2001; Eitle and Taylor 2008; Mears et al. 2009, 2013; Pickett et al. 2012). Likewise, research has explored several ways in which political threat has contributed to use of various criminal justice sanctions toward minorities (e.g., see Behrens et al. 2003; Eitle et al. 2002; Chiricos et al. 2012; Fredriksson 2017; Jacobs and Carmichael 2001; Uggen and Manza 2002). In contrast, analyses of economic threat are far less common in criminological research. Second, the United States has a history of notable anxieties over Whites losing jobs to racial/ethnic minorities (Chomsky 2018; Economic Cycle Research Institute 2016). Yet, it is less clear whether and how these anxieties translate into harsher criminal justice sanctions for minorities. Last, the limited research which has examined economic threat in the context of sentencing has used cross-sectional measures of threat (e.g., Jordan and Maroun 2016; Wang and Mears 2010)—such as the minority-to-White employment ratio at a single time point. While cross-sectional measures are helpful in broadly testing economic threat propositions, they miss a key piece of Blalock's (1967) original threat conceptualizationthat rising minority competition will trigger punitive treatment of minorities.

In light of these considerations, the goal of this study is to provide a comprehensive test of economic threat in sentencing by examining multiple time-varying measures of economic threat, as well as the standard racial/ethnic threat measures (i.e., minority population growth). To accomplish this goal, we use case-level data drawn from the Minnesota Sentencing Guidelines Commission dataset between 2007 and 2015 and countylevel data drawn from the publicly available United States Census Bureau's 2000 and 2010 Decennial Census.

\section{Race and Ethnicity in the Criminal Justice System}

Racial/ethnic minorities are disproportionately represented throughout the criminal justice system (Beck and Blumstein 2018). In 2018, Blacks made up 12\% of the population but $53 \%$ of homicide arrestees, $54 \%$ of robbery arrestees, and $34 \%$ of aggravated assault arrestees (Federal Bureau of Investigation 2018). At the pretrial stage, Blacks are around 3.5 times more likely to be incarcerated in a jail than Whites (The Sentencing Project 2018). 
More broadly, Blacks and Hispanics make up roughly $30 \%$ of the population but compose of over $57 \%$ of the prison population (The Sentencing Project 2018). Moreover, there are multiple other decision points that have produced racial/ethnic disparities in criminal justice outcomes-including sentencing (Mears et al. 2016).

Decades of sentencing research has highlighted that Blacks and (to a lesser extent) Hispanics are subject to increased odds of incarceration, longer average prison sentences, and lower odds of downward sentencing departures than similarly situated Whites (Baumer 2013; Franklin and Henry 2020; Light et al. 2014; Spohn 2000, 2013; Steffensmeier et al. 1998). In the absence of evidence of direct racial discrimination on the part of sentencing judges and court actors (Bushway and Piehl 2001), criminal justice scholars have sought to provide explanations as to why racial/ethnic disparities in sentencing outcomes persist. Some argue that persistent racial/ethnic effects are the result of judges "perceptual shorthands" of dangerousness, culpability, and practicality in the face of uncertainty and insufficient information (Albonetti 1991; Steffensmeier et al. 1998, 2017). Others argue that racial/ethnic effects are the byproduct of agency costs which promote individual court actors to limit the "political risk" in sentencing decisions by being harsh on those on the margins of society (Bibas 2015; Pfaff 2017; Stuntz 2011). However, one of the more prominent theories to explain racial/ethnic disparities in criminal justice outcomes has been Blalock's (1967) racial/ethnic threat theory. We now turn to a formal discussion of racial/ethnic threat.

\subsection{Racial/Ethnic Threat Theory}

According to Blalock's (1967) racial/ethnic threat theory, the criminal justice system may be used by those in power (typically Whites) to maintain their dominant position in society. In other words, racial/ethnic threat theory posits that when the majority group is threatened by a growing minority group, the majority group uses formal social control as a tool to maintain their advantaged position and control the growing minority group. Blalock (1967) also hypothesized that racial/ethnic threat operates in a curvilinear fashion, where the effect of growing minority groups on use of formal social controls either maxes out or switches directions once racial/ethnic minority populations reach a certain social standing.

Studies of racial/ethnic threat in the criminal justice system have historically focused on whether patterns of enforcement, sanctions, and punishment toward minority groups depend on the relative size of the minority group (i.e., percent black/minority population; growth in percent minority). From a racial/ethnic threat perspective, it is hypothesized that minority differences in criminal justice outcomes would be magnified in areas with large or growing minority populations (Blauner 1972; Liska 1992; Turk 1969). To date, there have been close to 100 studies which have examined the racial/ethnic threat perspective in the context of the criminal justice system (Feldmeyer and Cochran 2018). The results from these studies suggest that larger minority populations are associated with increased law enforcement expenditures (Chamlin 1989), increased law enforcement size (Kent and Jacobs 2004), increased Black death penalty cases (Jacobs et al. 2005), and increased White perceptions of the criminality of minorities (Chiricos et al. 2001; Mears et al. 2013). Similarly, there is now a large and growing body of research examining racial/ethnic threat in sentencing.

\subsection{Racial/Ethnic Threat and Sentencing}

As with other research testing racial/ethnic threat, the typical manner in which threat has been assessed in the sentencing literature is by examining whether minority defendants receive harsher sentencing outcomes than Whites in areas with larger or growing minority populations. Although evidence of racial/ethnic threat in sentencing is mixed (see Feldmeyer and Cochran 2018), many studies have found support for the theory. Growing minority populations have been linked to greater Black-White (and Hispanic-White) disparities in incarceration, sentence length, departures, and other sentencing outcomes, 
such as the death penalty or habitual offender designation (Caravelis et al. 2011, 2013; Feldmeyer et al. 2015; Jacobs and Carmichael 2001; Jacobs et al. 2005; Johnson 2005; Ulmer and Johnson 2004; Weidner et al. 2005).

Despite this supportive evidence, the research also shows that support for racial/ethnic threat at sentencing tends to be conditional on: (a) the dependent variable examined, (b) if or how the cross-level interaction is estimated, and (c) whether threat is separated by race/ethnicity. For example, Ulmer and Johnson (2004) found that larger minority populations increase disparities in sentence length but not incarceration. Alternatively, Light et al. (2014) found that rising minority populations increase minority disadvantage in incarceration but not sentence length. Ulmer and Bradley (2006) and Weidner and colleagues (2005) both found that larger racial/ethnic minority populations increase the expected sentence severity for all defendants-not just racial/ethnic minorities. Furthermore, Feldmeyer et al. (2015) found that Black defendants were more likely to be sentenced to prison and for longer periods of time in counties with growing Black populations. However, this finding was not replicated for Latinos. In a similar fashion, Johnson (2005) identified that rising Black populations' increased upward departure odds for Blacks, but rising Hispanic populations had null effects on upward departure odds for Hispanics.

All in all, the extant literature on racial/ethnic threat finds at least partial support for the theory, but the findings are not uniform across contexts and situations. Much more research is needed to gain a better understanding of how racial/ethnic threat operates in practice. Moreover, the literature reviewed above focuses primarily on tests of general $\mathrm{racial} / \mathrm{ethnic}$ threat, but has given little attention to some of the more acute forms of threat outlined by Blalock (1967)—particularly economic threat.

\subsection{Economic Threat}

One potential reason for the lack of clarity in the racial/ethnic threat and sentencing literature is that extant work has seldom explored the totality of theoretical propositions suggested by Blalock (1967). Racial/ethnic threat perspective is not only hypothesized to operate based on the population growth of minorities (Feldmeyer and Ulmer 2011; Feldmeyer et al. 2015; Johnson et al. 2008). Rather, Blalock (1967) suggests that racial/ethnic threat can operate in numerous ways, including political threat, criminal threat, and economic threat. Economic threat-the focus of this study-suggests that in areas where $\mathrm{racial} / \mathrm{ethnic}$ minorities are gaining more economic resources and increasingly competing with Whites for their share of the proverbial "economic pie," Whites will use the criminal justice system to "tame" minority advancement. Similar to the general racial/ethnic threat, Blalock (1967) suggested that economic threat may operate in a curvilinear fashion where growing minority competition will result in growing levels of social control up to a point; however, when minorities become "successfully integrated," increases in minority economic competition may no longer trigger the same punitive response.

While all types of threat-political, criminal, and economic - warrant further empirical attention, there are at least three reasons why it is particularly important to examine economic threat. First, criminal and political threat have been assessed in prior criminal justice research more consistently than economic threat. For example, prior research has assessed the effect of criminal threat on arrest rates and public fear of crime (e.g., D'Alessio et al. 2002; Eitle et al. 2002; Eitle and Taylor 2008; Mears et al. 2009, 2013; Pickett et al. 2012; Stolzenberg et al. 2004), and political threat has often been considered in research on felon disenfranchisement (e.g., Behrens et al. 2003; Chiricos et al. 2012; Fredriksson 2017; Jacobs and Carmichael 2001). However, in terms of economic threat, only a small handful of studies have tested its theoretical propositions (Britt 2000; Jordan and Maroun 2016; Wang and Mears 2010). Second, there is a long history in the United States of economic anxieties surrounding the loss of jobs to racial/ethnic minority groups (Chomsky 2018). One must look no further than the 2016 Presidential campaign to see worries and anxieties about racial/ethnic minorities "stealing" jobs. In a 2015 speech to his constituents the eventual President Donald Trump touted his get tough on immigration policy using the quote of 
“They're taking our jobs. They're taking our manufacturing jobs. They're taking our money. They're killing us," (Hoban 2017). Third, there is some evidence that White jobs have been decreasing over the past 15-to-20 years while racial/ethnic minority jobs have been increasing. Explicitly, from 2007 to 2016 the Economic Cycle Research Institute (2016) estimates that the American economy netted a positive 5 million jobs: $56 \%$ of those gains went to Hispanics, $25 \%$ of those gains went to Blacks, and Whites netted a $9 \%$ loss. In sum, there are multiple reasons to suspect that economic threat towards minorities exists and may have risen in the early decades of the 21st century. However, questions remain about whether economic threat contributes to harsher punitiveness toward minorities, especially in sentencing decisions.

A few notable studies have begun to examine how economic threat influences minority outcomes across the criminal justice system (Eitle et al. 2002; Stolzenberg et al. 2004). Focusing specifically on studies which have explored economic threat in sentencing (Britt 2000; Carmichael 2005, 2010; Jordan and Maroun 2016; Wang and Mears 2010) support for economic threat has been mixed, but largely null. To illustrate, Jordan and Maroun (2016) found that counties with higher levels of Black economic threat (measured as White-toBlack unemployment differences) sentence defendants overall to incarceration at lower rates but to longer periods of incarceration. Meanwhile, other studies have reported no significant effects of economic threat at sentencing (Britt 2000; Carmichael 2010; Wang and Mears 2010). ${ }^{1}$

Although these studies have been influential in laying the groundwork for economic threat research, there are some theoretical inconsistencies in the way that economic threat is operationalized. For example, both Wang and Mears (2010) and Jordan and Maroun (2016) use static measures of economic threat: the White-to-Black (and White-to-Hispanic) unemployment ratio from the 2000 Decennial Census. While static measures of threat are useful in broadly testing economic threat, they omit a key component of Blalock's (1967) original group threat perspective: that rising minority competition, not simply a stable presence of competition, will trigger more punitive treatment of minority groups. The differentiation between the static and dynamic operationalization of threat variables has been particularly important in past racial/ethnic threat research. Caravelis et al. (2011) found that counties with large Black populations have smaller Black-White disparities in sentencing outcomes but counties with rising Black populations have larger Black-White sentencing disparities. Similarly, Caravelis and colleagues (2011) found that counties with large Hispanic populations have smaller Hispanic-White differences at sentencing but counties with rising Hispanic populations have larger Hispanic-White sentencing disparities. Thus, in light of (a) the theoretical inconsistency in the way that past sentencing studies have operationalized economic threat and (b) past research which suggests that the way that threat measures are operationalized can impact the conclusions of the study, there is a pressing need for research which uses dynamic as opposed to static measures of economic threat.

\section{Current Study}

Given the flurry of racial/ethnic threat studies over the past two decades, the relative dearth of research examining economic threat is surprising. In light of this, the goal of this study is to extend the current state of the literature on racial/ethnic threat at sentencing by (a) incorporating a direct test of economic threat alongside the typical racial/ethnic threat test using minority population composition and (b) using a dynamic measure of economic threat to better align with Blalock's (1967) original propositions. Furthermore, this study also contributes to sentencing research and the racial/ethnic threat literature by examining these relationships in a state court system-Minnesota-which has received relatively little attention in the sentencing literature. In order to achieve the study goals, we use sentencing data spanning across each of Minnesota's 87 counties from 2007 to 2015.

In the current study we test racial/ethnic and economic threat both broadly and specifically. From a theoretical perspective, racial/ethnic threat has been proposed to operate 
when the minority group threatens the status of the dominant group in society (Blauner 1972; Liska 1992; Turk 1969). As such, it may not matter that Black or Hispanic populations specifically are competing for resources but rather that minority populations, as a whole, are doing so. To test this broader minority threat proposition, we first test racial/ethnic and economic threat by combining Black and Hispanic populations into a single minority measure (e.g., minority defendant, minority population growth, minority-White employment competition). Second, to supplement the broader minority-group approach, we also estimate models separately for Black and Hispanic defendants and population measures (e.g., Black defendant, Hispanic defendant, Black population growth, Hispanic-White economic competition). By using these two methods of measuring racial/ethnic and economic threat, we aim to provide a rigorous estimation of minority threat while still considering the potential differential effects of Black and Hispanic threat. Drawing on general tests of racial/ethnic threat that rely on the relative size of the minority population to capture threat, we predict the following:

Hypothesis 1 (H1). Counties with growing minority (or Black or Hispanic) populations will have larger (a) minority-White, (b) Black-White, and (c) Hispanic-White differences in sentencing outcomes (i.e., incarceration, sentence length).

Drawing from prior research and theory focusing on economic threat, we also examine two measures of economic threat across minority groups and specific racial/ethnic groupsminority-White employment competition and the \% of minorities living above the poverty line. According to the economic threat perspective, we would expect that as minorityWhite employment competition grows and as minority groups gain economic status (higher rates of minorities living above the poverty line) they may pose a greater economic threat to the White majority. Based on these assumptions, we predict the following:

Hypothesis 2 (H2). Counties with increasing minority-White (or Black or Hispanic versus White) employment competition will have larger (a) minority-White, (b) Black-White, and (c) Hispanic-White differences in sentencing outcomes (i.e., incarceration, sentence length).

Hypothesis 3 (H3). Counties with an increasing \% of minorities (or Blacks or Hispanics) living above the poverty line will have larger (a) minority-White, (b) Black-White, and (c) Hispanic-White differences in sentencing outcomes (i.e., incarceration, sentence length).

\section{Method}

\subsection{Data and Sample}

Data for this study are nested at two-levels: (1) case and (2) county. Case-level data come from the Minnesota Sentencing Guidelines Commission (MSGC). The MSGC was established in 1978 and led to the creation of presumptive sentencing guidelines in Minnesota state courts. The guidelines were developed as a sentencing matrix with an 11-category offense seriousness vector on the $y$-axis and a 7-category criminal history vector on the $x$-axis. To calculate the appropriate sentence, judges are instructed to find the intersection of the offense seriousness and criminal history vectors on the guideline matrix. The cells provide judges with two key pieces of information. First, the shading of the cell (or lack thereof) represents the type of sentence recommended. If a cell is shaded grey, the recommended sentence is to a local jail or other community alternative (e.g., probation). Meanwhile, if the cell is not shaded (or White) the recommended sentence is a state prison commitment (Frase 2005). Second, each cell provides a presumptive sentence length (and range, if state prison is recommended) in months.

The MSGC dataset includes detailed information about each defendant's demographic characteristics, current offenses, criminal history, and sentencing. The data for this study includes cases sentenced under the Minnesota sentencing guidelines between January 2007 and December 2015. The full sample included 138,715 felony cases; however, three groups of cases were excluded from analysis for practical reasons. First, defendants sentenced for 
sexual offenses were removed from the sample because these defendants are sentenced using a separate sentencing guideline specific to sex offenses (see Minnesota Sentencing Guidelines Commission 2019). Second, racial/ethnic threat has historically been applied to Black and Hispanic defendants (Blalock 1967; Johnson 2005; Wang and Mears 2010). Therefore, only Black $(n=36,249)$, Hispanic $(n=7764)$, and White $(n=77,773)$ defendants are maintained in the analytic sample, while American Indian $(\mathrm{n}=9474)$, Asian $(\mathrm{n}=3279)$, and Other $(n=17)$ defendants are removed from the sample. ${ }^{2}$ Third, data with coding inconsistencies $(n=120)$ are removed from analysis due to potential coding errors in the original data. ${ }^{3}$ After removing these cases, the final analytic case-level sample contained 121,666 cases sentenced in Minnesota state courts from January 2007 to December 2015.

County-level data come from the 2000 and 2010 United States Census Bureau's Decennial Census estimates. We use both the 2000 and 2010 estimates - rather than the 2000 or 2010 estimates only - to create dynamic measures of racial/ethnic and economic threat (e.g., change in \% minority, change in minority-to-White employment competition). Importantly, the MSGC (case-level) dataset provides information on the county in which a defendant is sentenced; thus, we are able to match defendants to counties to assess the direct and contextual influence of social structural characteristics on sentencing outcomes.

\subsection{Measures}

\subsubsection{Dependent Variables}

Consistent with past sentencing research, we conceptualize sentencing as a two-step process: (1) the decision to incarcerate and (2) the decision of how long to incarcerate (Doerner and Demuth 2010; Feldmeyer et al. 2015). Incarceration is measured dichotomously indicating whether a defendant was sentenced to state prison $(1=$ Prison; $0=$ No Prison). Sentence length is measured continuously representing the number of months a defendant was sentenced to state prison. Due to the heavy right skew of sentence length, we use the natural log of the measure in regression models. Using the natural log of sentence length is a common analytic technique in sentencing research to isolate the effects of independent variables on the length of sentence ordered (see Doerner and Demuth 2010; Ulmer and Parker 2020). ${ }^{4}$

\subsubsection{Case-Level (Level 1) Independent Variables}

The main case-level independent variable is defendant race/ethnicity, which is coded in two separate ways. First, to broadly test racial/ethnic and economic threat we created a "minority" variable which represents whether the defendant is a racial/ethnic minority ( 1 = Black or Hispanic; ref. = White). Second, similar to past research which finds differential effects between Black and Hispanic defendants (Feldmeyer et al. 2015; Johnson 2005), we break the minority variable down into separate Black $(1=$ Black; ref. $=$ White $)$ and Hispanic (1 = Hispanic; ref. = White) categories. By measuring race/ethnicity in these two ways, we provide a strong statistical estimation of minority threat, while still considering the potential differential effects of Black and Hispanic threat.

Similar to prior sentencing research, we also include controls for defendant age and sex (Steffensmeier et al. 1998). Age is measured as a continuous variable and represents the defendant's age (in years) at the time of sentencing. Aligning with past sentencing research which finds that age has a curvilinear effect on sentencing outcomes, we also include a squared-term for age in the analyses (Doerner and Demuth 2010; Holmes and D'Amato 2020). Defendant se $x$ is coded dichotomously $(1=$ Male; ref. $=$ Female $)$.

In addition to these extralegal variables noted above, we also include several key legal variables. We include two guideline related measures: presumptive sentence and criminal history. Presumptive sentence is measured as the number of months of incarceration recommended by the Minnesota Sentencing Guideline matrix. Due to overdispersion of presumptive sentence, we use the natural $\log$ of the variable in regression models. Criminal history is measured on a scale of 0 to 6 , with higher scores representing a more extensive criminal history. While presumptive sentence does capture some aspects of a 
defendant's criminal history, past research has found that the effect of criminal history on sentencing outcomes extends beyond the influence of the presumptive sentence (Holmes and Feldmeyer 2019; Ulmer 2000). In addition to these guideline measures, we control for several additional case-level characteristics using a series of dichotomous variables: pretrial detention $(1=$ Yes; ref. $=$ No), focal offense type $(1=$ Person, Property, Driving While Intoxicated (DWI), Weapons, Other; ref. = Drug), mode of disposition $(1=$ Trial; ref. = Plea), multiple offenses ( $1=2+$ offenses; ref. $=1$ offense), and sentencing year $(1=2008,2009$, 2010, 2011, 2012, 2013, 2014, 2015; ref. = 2007). Last, in the sentence length model only, we control for downward departure, which captures whether a defendant was granted a sentence below the minimum guideline range $(1=$ downward departure; $0=$ no downward departure). Notably, the Minnesota Sentencing Guidelines only include sentencing ranges for those cells with presumptive state prison sentences-making a control for departure at the incarceration decision singularly predictive.

\subsubsection{County-Level (Level 2) Independent Variables}

In order to test racial/ethnic and economic threat, we include several measures capturing change in racial/ethnic context and economic competition within Minnesota counties. The U.S. Census Bureau provides mutually exclusive measures of Hispanic ethnicity (i.e., White non-Hispanic, Black non-Hispanic, Hispanic). Using the categories provided by the U.S. Census Bureau, measures were created initially for total minority populations and then separately for Black and Hispanic groups. Following the practice of prior research, we measure racial/ethnic threat as the change in \% minority population in a county from 2000 to 2010. Likewise, in the Black and Hispanic models, we measure racial/ethnic threat as the change in \% Black population and the change in \% Hispanic population (respectively) in a county from 2000 to 2010.

To capture economic threat, we rely on two indicators of economic competition: (1) county-level change in minority-to-White employment competition and (2) county-level change in \% of minorities living above the poverty line. Operationalizing economic threat as a minorityto-White employment competition and \% minority above the poverty line is consistent with past research assessing economic threat (Eitle et al. 2002; Wang and Mears 2010). However, by assessing the change in these measures over time and treating them as dynamic, we are able to capture the change aspect Blalock's (1967) original depiction of the theory (see Feldmeyer and Cochran 2018; Caravelis et al. 2011).

Change in the minority-to-White employment competition is created by dividing the minority unemployment rate by the White unemployment rate in 2000 and 2010, respectively, and then subtracting the 2000 values from the 2010 values. ${ }^{5}$ In its base form, larger values would reflect rising minority unemployment relative to Whites and less economic competition. In order to ease interpretation of results, we reverse coded these measures (multiplying the ratio by -1 ) so that positive values indicate increasing economic threat and negative values indicate decreasing economic threat. This measure is also calculated separately for Black and Hispanic populations to capture county-level changes in BlackWhite and Hispanic-White employment competition from 2000 to 2010. Both change in Black-White and Hispanic-White employment competition variables are also inversed (multiplied by -1 ).

The second economic threat measure is the county-level change in \% minorities above the poverty line between 2000 to 2010 (e.g., $2010 \%$ minorities living above the poverty line minus $2000 \%$ minorities living above the poverty line within each county). Positive values in this variable represent a growing number of minorities living above the poverty line (i.e., an increase in economic threat). Negative values represent a shrinking $\%$ of minorities living above the poverty line (i.e., a decrease in economic threat). Again, this measure is calculated separately for Black and Hispanic populations to capture changes in Black and Hispanic poverty within counties from 2000 to 2010.

Drawing from prior research examining macrolevel influences on sentencing, we also include county-level population size as a control variable as prior research shows 
sentencing differences in smaller versus larger counties (Feldmeyer et al. 2015; Wang and Mears 2010). Total population reflects the average population size of each county using the 2000 and 2010 Decennial Census measures. Total population is log transformed to account for skewness in the variable and help improve model fit (Raudenbush and Bryk 2002). ${ }^{6}$

\subsection{Analytic Strategy}

In order to address our research hypotheses, we use multilevel modeling. A multilevel framework is needed for a few reasons. First, the multilevel model adjusts the degrees of freedom for predictors at higher levels-counties in the context of this study. Where a single level model would base county-level hypotheses on the case-level sample size, the multilevel model adjusts the level 2 tests to their appropriate units. Second, cases handled within the same county are likely to be handled similarly to each other and thus cannot be treated as independent (Light et al. 2014; Ulmer and Johnson 2004; Ulmer et al. 2010). The multilevel framework incorporates random effects for each county-accounting for the interdependence of cases within counties. Last, multilevel models allow for cross-level interactions between higher-level and lower-level predictors. These cross-level interactions are key to the tests of racial/ethnic and economic threat hypotheses: examining whether the social structural context of counties (racial/ethnic population composition, racial/ethnic economic competition) influence racial/ethnic disparity (Raudenbush and Bryk 2002).

The incarceration decision is modeled using multilevel logistic regression. The sentence length decision is modeled using multilevel ordinary least squares (OLS) regression. The first step in a multilevel approach is to examine unconditional models with no caseor county-level predictors in the model. The purpose of the unconditional models is to indicate whether the odds of incarceration, or length of sentenced ordered, significantly varies across counties. Significant variance in incarceration odds $\left(\chi^{2}=1818.18 ; p<0.001\right)$ and sentence length $\left(\chi^{2}=472.27 p<0.001\right)$ are found using the current study data. Therefore, a multilevel model which nests cases within counties is appropriate to examine our study hypotheses.

The results of all models are reported based on population-average models, and all variables are grand mean centered to allow for compositional effects of lower-level predictors on higher-levels of analysis (for similar centering practices see Light et al. 2014). The main independent variables_-defendant race/ethnicity — are allowed to vary randomly across counties; however, as will be discussed more in the results and discussion section, the Hispanic effect does not vary randomly across counties in either of the racial/ethnic-specific incarceration or sentence length models. As such, Hispanic effects in the racial/ethnicspecific models presented are fixed.

The analysis takes place in three steps. First, we examine the descriptive statistics of the dependent, independent, and control variables. Second, we assess our minority threat and minority economic threat hypotheses. In order to test these propositions, we begin by running case-level random coefficient logistic and OLS regression models. These case-level regression models inform us of (a) the average minority effect on the odds of incarceration and length of sentence ordered net of theoretically and empirically relevant factors and (b) whether the minority effect varies randomly across counties. Given that the minority variable does vary randomly across counties, we then conduct cross-level interactions between our county-level predictors of interest and minority defendant status. The crosslevel interactions inform us of whether rising minority populations, or the economic threatening of minority populations, in Minnesota counties contextualize minority-White differences at sentencing.

Third, to conclude the analysis, we replicate the above steps for overall minorities separately for both Blacks and Hispanics, compared to Whites. ${ }^{7}$ Some of the smaller counties in Minnesota are racially and ethnically homogenous in terms of the makeup of the workforce. As a result, the models testing our Black threat hypotheses include cases spanning 79 of the 87 Minnesota counties and the models testing our Hispanic threat hypotheses include cases spanning 85 of the 87 Minnesota counties. ${ }^{8}$ Furthermore, because 
of the limited county-level sample size ( $\mathrm{n} \leq 87$ across all models), we use a significance value of $p<0.10$ as the cutoff for identifying a county-level (level 2) regression coefficient as statistically significant. Although a significance level of $p<0.10$ may be seen as liberal, the use of this significance level is common in research examining the higher-level effects of sentencing predictors (Sampson and Laub 1993; Ulmer and Johnson 2004). For case-level (level 1) regression coefficients, we use the standard alpha level of $p<0.05$ (Feldmeyer and Ulmer 2011; Ulmer and Parker 2020). Finally, aligning Blalock's (1967) threat theory which hypothesizes a curvilinear relationship between threat variables and sentencing outcomes, we initially estimated supplemental models which included a squared-term for the racial/ethnic and economic threat variables. However, no significant curvilinear relationships were identified in any of the models. As such, these squared terms were removed from the final analysis, a point we return to in the discussion.

\section{Results}

The descriptive statistics for both the incarceration and sentence length samples are displayed in Table 1. Among the analytic sample, $25 \%$ of defendants are sentenced to state prison. In the incarceration sample, $36 \%$ of defendants are minorities (30\% Black, $6 \%$ Hispanic), while the remaining defendants are White (64\%). Over $80 \%$ of the sample is male and the average age of a defendant is just over 30 years. As for legal variables, the average presumptive sentence length is about 28 months, while $39 \%$ of the sample is detained pretrial (compared to released). The average criminal history score is just under 2, on a scale from 0 to 6 . Most defendants are convicted of a focal drug (26\%), person (30\%), or property offense $(31 \%)$. Further, most cases are settled via a plea deal $(97 \%)$ compared to trial (3\%) and had one offense ( $95 \%$ ) compared to two or more (5\%). Across years, the cases are relatively evenly distributed.

Table 1. Descriptive Statistics.

\begin{tabular}{|c|c|c|c|c|}
\hline & \multicolumn{2}{|c|}{$\begin{array}{l}\text { Incarceration Sample } \\
\text { (Case-Level } N=121,666) \\
\text { (County-Level } N=87 \text { ) }\end{array}$} & \multicolumn{2}{|c|}{$\begin{array}{c}\text { Sentence Length Sample } \\
\text { (Case-Level } N=30,046) \\
\text { (County-Level } N=87 \text { ) }\end{array}$} \\
\hline & $\%$ or Mean & $S D$ & $\%$ or Mean & $S D$ \\
\hline \multicolumn{5}{|l|}{ Dependent Variables } \\
\hline \multicolumn{5}{|l|}{ State Prison } \\
\hline No & $75 \%$ & - & - & - \\
\hline Yes & $25 \%$ & - & - & - \\
\hline Sentence Length (Months) & - & - & 45.493 & 46.978 \\
\hline Case Level Variables & - & - & - & - \\
\hline \multicolumn{5}{|l|}{ Minority } \\
\hline No & $64 \%$ & - & $55 \%$ & - \\
\hline Yes & $36 \%$ & - & $45 \%$ & - \\
\hline \multicolumn{5}{|l|}{ Race/Ethnicity } \\
\hline White & $64 \%$ & - & $55 \%$ & - \\
\hline Black & $30 \%$ & - & $38 \%$ & - \\
\hline Hispanic & $6 \%$ & - & $7 \%$ & - \\
\hline \multicolumn{5}{|l|}{ Sex } \\
\hline Female & $17 \%$ & - & $8 \%$ & - \\
\hline Male & $83 \%$ & - & $92 \%$ & - \\
\hline Age at sentencing & 32.418 & 10.754 & 33.612 & 10.267 \\
\hline Presumptive sentence & 27.665 & 31.049 & 50.376 & 49.068 \\
\hline \multicolumn{5}{|l|}{ Pretrial detention } \\
\hline No & $61 \%$ & - & $43 \%$ & - \\
\hline Yes & $39 \%$ & - & $57 \%$ & - \\
\hline
\end{tabular}


Table 1. Cont.

\begin{tabular}{|c|c|c|c|c|}
\hline & \multicolumn{2}{|c|}{$\begin{array}{l}\text { Incarceration Sample } \\
\text { (Case-Level } N=121,666) \\
\text { (County-Level } N=87 \text { ) }\end{array}$} & \multicolumn{2}{|c|}{$\begin{array}{c}\text { Sentence Length Sample } \\
\text { (Case-Level } N=30,046) \\
\text { (County-Level } N=87 \text { ) }\end{array}$} \\
\hline & $\%$ or Mean & $S D$ & $\%$ or Mean & $S D$ \\
\hline Criminal history & 1.866 & 1.999 & 3.654 & 2.112 \\
\hline \multicolumn{5}{|l|}{ Offense type } \\
\hline Drug & $26 \%$ & - & $27 \%$ & - \\
\hline Person & $31 \%$ & - & $35 \%$ & - \\
\hline Property & $32 \%$ & - & $25 \%$ & - \\
\hline DWI & $4 \%$ & - & $5 \%$ & - \\
\hline Weapons & $3 \%$ & - & $6 \%$ & - \\
\hline Other & $5 \%$ & - & $3 \%$ & - \\
\hline \multicolumn{5}{|l|}{ Mode of Disposition } \\
\hline Plea & $97 \%$ & - & $93 \%$ & - \\
\hline Trial & $3 \%$ & - & $7 \%$ & - \\
\hline \multicolumn{5}{|l|}{ Multiple offenses } \\
\hline No & $95 \%$ & - & $91 \%$ & - \\
\hline Yes & $5 \%$ & - & $9 \%$ & - \\
\hline \multicolumn{5}{|l|}{ Downward departure } \\
\hline $\mathrm{No}$ & - & - & $76 \%$ & - \\
\hline Yes & - & - & $24 \%$ & - \\
\hline \multicolumn{5}{|l|}{ Year } \\
\hline 2007 & $12 \%$ & - & $11 \%$ & - \\
\hline 2008 & $11 \%$ & - & $11 \%$ & - \\
\hline 2009 & $11 \%$ & - & $11 \%$ & - \\
\hline 2010 & $10 \%$ & - & $10 \%$ & - \\
\hline 2011 & $11 \%$ & - & $10 \%$ & - \\
\hline 2012 & $11 \%$ & - & $11 \%$ & - \\
\hline 2013 & $11 \%$ & - & $12 \%$ & - \\
\hline 2014 & $12 \%$ & - & $12 \%$ & - \\
\hline 2015 & $12 \%$ & - & $12 \%$ & - \\
\hline County-Level Variables & \multicolumn{2}{|c|}{ Mean } & \multicolumn{2}{|c|}{$S D$} \\
\hline $\begin{array}{l}\text { Change in minority-to-White employment } \\
\text { competition }\end{array}$ & \multicolumn{2}{|c|}{0.111} & \multicolumn{2}{|c|}{2.240} \\
\hline $\begin{array}{l}\text { Change in Black-to-White employment } \\
\text { competition a }\end{array}$ & \multicolumn{2}{|c|}{-0.137} & \multicolumn{2}{|c|}{7.201} \\
\hline $\begin{array}{l}\text { Change in Hispanic-to-White employment } \\
\text { competition } b\end{array}$ & \multicolumn{2}{|c|}{0.356} & \multicolumn{2}{|c|}{2.622} \\
\hline Change in $\%$ minorities above the poverty line & \multicolumn{2}{|c|}{-4.055} & \multicolumn{2}{|c|}{17.110} \\
\hline Change in \% Blacks above the poverty line ${ }^{a}$ & \multicolumn{2}{|c|}{-8.193} & \multicolumn{2}{|c|}{31.545} \\
\hline Change in \% Hispanics above the poverty line ${ }^{b}$ & \multicolumn{2}{|c|}{-4.346} & \multicolumn{2}{|c|}{18.152} \\
\hline Change in $\%$ minority population & \multicolumn{2}{|c|}{-2.017} & \multicolumn{2}{|c|}{1.986} \\
\hline Change in \% Black population ${ }^{a}$ & \multicolumn{2}{|c|}{0.637} & \multicolumn{2}{|c|}{0.765} \\
\hline Change in $\%$ Hispanic population ${ }^{b}$ & \multicolumn{2}{|c|}{1.448} & \multicolumn{2}{|c|}{1.571} \\
\hline Total population & & & 142 & \\
\hline
\end{tabular}

Notes: SD = Standard Deviation; DWI = Driving while intoxicated; Percentages are displayed for binary variables; Means are displayed for continuous variables; $S D$ omitted for binary variables; Change in minority/Black/Hispanic-to-White employment competition was multiplied by -1 to reverse the direction of the variable. ${ }^{a}$ The county sample size for these measures is 79 due to 8 counties having no Black individuals in the labor force in a given year. ${ }^{b}$ The county sample size for these measures is 85 due to 2 counties having no Hispanic individuals in the labor force in a given year.

As for the sample of defendants who were sentenced to state prison, the average sentence length is about 45.5 months. The defendant and case characteristics for the sentence length sample are similar to the incarceration sample with a few notable differences. First, sentence length sample has a higher concentration of racial/ethnic minorities than the incarceration sample ( $45 \%$ overall; $38 \%$ Black, $7 \%$ Hispanic). Second, the presumptive sentence is greater, on average, in the sentence length sample than the incarceration sample (about 51 months vs. about 28 months). Third, more than half of those sentenced to state prison 
were detained pretrial (57\%); whereas the majority of defendants sentenced overall were released pretrial (61\%). Last, defendants who were sentenced to state prison had higher criminal history scores (3.654), on average, than the average defendant sentenced (1.866).

Turning to our racial/ethnic threat variables, the average change in minority population across counties from 2000 to 2010 is $2.02 \%$, indicating that county minority percentages grew on average during this period. Similarly, both the Black and Hispanic population percentages grew between 2000 and 2010 ( $0.64 \%$ and $1.46 \%$, respectively).

As for our economic threat measures, the average change in minority-to-White employment competition (when reverse coded) in counties between 2000 and 2010 is 0.111 , with this change ranging from -6.757 to 6.853 . This indicates that between 2000 and 2010, the average county experienced a slight increase in the percent of employed minorities in comparison to employed Whites-a sign of rising minority economic competition or threat. The opposite is found for Black employment specifically. The average change in Black-to-White employment competition in counties between 2000 and 2010 is -0.137 , which indicates that Black employment shrunk (relative to Whites) and suggests a decline in Black economic threat. In contrast, the average change in Hispanic-to-White employment competition in counties between 2000 and 2010 is 0.356 , which signals a closing gap between Hispanic and White unemployment and greater Hispanic economic threat. All in all, these bivariate patterns suggest that Hispanics have been making economic strides over this time period-but not Blacks. The reader should note that Hispanics making strides in the economic sphere aligns with the Economic Cycle Research Institute (2016) report which finds that Hispanic job growth has been particularly large.

Turning to the county poverty variables (our other economic threat measure), the average change in the \% of minorities living above the poverty line between 2000 and 2010 is $-4.055 \%$, which signals a decrease in minorities living above the poverty line and a decline in economic competition or threat. Similarly, the average change in \% Black and Hispanics living above the poverty line are also negative $(-8.193 \%$ and $-4.346 \%$, respectively), signaling decreases in minorities living above the poverty line within counites for both groups from 2000 to 2010 and weaker economic positions (i.e., less "threat" or economic competition).

\subsection{Multivariable Analyses: Minority Threat}

We begin our multivariable analysis by examining sentencing outcomes for minorities broadly (Black and Hispanic defendants combined). Table 2 presents the random coefficient case-level logistic and OLS regression models isolating the minority effect on the odds of incarceration and length of sentence ordered, respectively. The findings from Table 2 indicate that minority defendants have higher odds (18.4\% larger) of receiving a state prison sentence than comparable White defendants. However, minority defendants receive significantly shorter sentences (about 1.3\% shorter) than similarly situated White defendants. Note that minority disadvantage at incarceration is similar to prior sentencing research but the negative relationship between minority and sentence length is contrary to some prior research (Doerner and Demuth 2014; Holmes and Feldmeyer 2019; Spohn 2000). 
Table 2. Hierarchical Regression of Incarceration and Sentence Length, 2007-2015 Case-Level Effects.

\begin{tabular}{|c|c|c|c|c|c|c|}
\hline \multirow[b]{2}{*}{ Variable } & \multicolumn{3}{|c|}{ Incarceration } & \multicolumn{3}{|c|}{ Sentence Length } \\
\hline & $b$ & $S E$ & $\operatorname{Exp}(b)$ & $b$ & $S E$ & $\%$ Change \\
\hline Minority & $0.169^{* * *}$ & 0.027 & 1.184 & $-0.013^{* *}$ & 0.005 & -1.3 \\
\hline Male & $0.266^{* * *}$ & 0.040 & 1.305 & $0.018^{* * *}$ & 0.004 & 1.8 \\
\hline Age at sentencing & $-0.028^{* * *}$ & 0.006 & 0.973 & -0.002 & 0.002 & - \\
\hline Age at sentencing squared & $0.001^{* * *}$ & 0.000 & 1.001 & 0.000 & 0.000 & - \\
\hline Presumptive sentence & $1.949^{* * *}$ & 0.079 & 7.019 & $0.903 * * *$ & 0.012 & 146.7 \\
\hline Pretrial detention & -0.005 & 0.032 & - & $-0.020 * * *$ & 0.002 & -2.0 \\
\hline Criminal history & $0.561^{* * *}$ & 0.021 & 1.751 & $-0.021 * * *$ & 0.001 & -2.1 \\
\hline \multicolumn{7}{|l|}{ Offense type } \\
\hline Person & -0.094 & 0.094 & - & 0.031 & 0.022 & - \\
\hline Property & $-0.156^{\wedge}$ & 0.082 & 0.855 & $0.042^{* *}$ & 0.013 & 4.3 \\
\hline DWI & $-1.147^{* * *}$ & 0.068 & 0.317 & 0.050 & 0.035 & - \\
\hline Weapons & $0.840^{* * *}$ & 0.218 & 2.316 & $0.462 * * *$ & 0.043 & 58.7 \\
\hline Other & -0.105 & 0.119 & - & 0.031 & 0.032 & - \\
\hline Trial & $1.039^{* * *}$ & 0.053 & 2.827 & $0.093^{* * *}$ & 0.005 & 9.7 \\
\hline Downward departure & & & & $-0.313^{* * *}$ & 0.006 & -26.9 \\
\hline Multiple offenses & -0.164 & 0.090 & - & $0.026^{* * *}$ & 0.008 & 2.6 \\
\hline \multicolumn{7}{|l|}{ Year } \\
\hline 2008 & -0.010 & 0.024 & - & 0.000 & 0.090 & - \\
\hline 2009 & -0.034 & 0.038 & - & -0.013 & 0.005 & - \\
\hline 2010 & -0.006 & 0.052 & - & -0.003 & 0.006 & - \\
\hline 2011 & $-0.086^{*}$ & 0.038 & 0.917 & 0.002 & 0.005 & - \\
\hline 2012 & -0.025 & 0.038 & - & 0.013 & 0.010 & - \\
\hline 2013 & 0.032 & 0.031 & - & 0.009 & 0.017 & - \\
\hline 2014 & $-0.114^{*}$ & 0.058 & 0.892 & 0.006 & 0.015 & - \\
\hline 2015 & -0.028 & 0.054 & - & 0.018 & 0.015 & - \\
\hline Intercept & $-1.671^{* * *}$ & 0.041 & - & $3.563^{* * *}$ & 0.004 & - \\
\hline \multicolumn{7}{|l|}{ Number of Observations } \\
\hline Case (Level 1) & & 121,666 & & & 30,046 & \\
\hline County (Level 2) & & 87 & & & 87 & \\
\hline $\begin{array}{l}\text { Variance Component } \\
\text { Minority }\end{array}$ & \multicolumn{3}{|c|}{ Standard Deviation } & \multicolumn{3}{|c|}{ Standard Deviation } \\
\hline
\end{tabular}

Notes: SE = Standard error; DWI = Driving while intoxicated; Drug offense is reference for Offense type; 2007 is the reference year for Year; Downward departure is excluded from the incarceration model because departures from Minnesota sentencing guidelines only impact sentences length. ^ $p<0.10 ;{ }^{*} p<0.05 ;{ }^{* *} p<0.01 ;{ }^{* * *} p<0.001$.

Turning briefly to the case-level extralegal controls, the findings from Table 2 largely align with prior sentencing research. Males are more likely to receive a prison sentence and receive longer average prison sentences than similarly situated female defendants. A curvilinear relationship between age and sentencing is detected at incarceration but not sentence length decision. Defendants with higher presumptive sentences are more likely to receive a prison sentence, and receive longer average sentences, than those with lower presumptive sentences. Criminal history acts as an aggravating factor at incarceration but a mitigating factor at sentence length. Defendants who stand trial are more likely to receive incarceration and receive longer average sentences than those who settle their case via plea. Looking at offense types, defendants convicted of DWI as their focal offense are less likely to be sentenced to prison than defendants with focal drug convictions. Meanwhile, defendants convicted on focal weapon offenses have higher odds of a prison sentence and receive longer average prison sentences than those convicted of focal drug offenses. At sentence length, defendants who receive a downward departure, are convicted on a single offense, and who are detained pretrial receive shorter average prison sentences.

The top of Table 3 displays the direct effects of the county-level variables on the average odds of incarceration and length of sentence ordered. The direct effects of racial/ethnic and economic threat suggest that no variables have a statistically significant relationship with county-level rates of incarceration or sentence length. However, logged population size has 
a marginally significant and negative relationship with incarceration $(p=0.073)$, suggesting that larger counties have lower average odds of incarceration than smaller counties.

Table 3. Hierarchical OLS Regression Model of Incarceration and Sentence Length, County-Level Effects with Cross-Level Interactions.

\begin{tabular}{|c|c|c|c|c|}
\hline \multirow[b]{2}{*}{ Variable } & \multicolumn{2}{|c|}{ Incarceration } & \multicolumn{2}{|c|}{ Sentence Length } \\
\hline & $b$ & $S E$ & $b$ & $S E$ \\
\hline Change in minority-to-White employment competition & -0.026 & 0.020 & 0.002 & 0.001 \\
\hline Change in $\%$ minorities above the poverty line & 0.001 & 0.002 & -0.000 & 0.000 \\
\hline Change in minority population & 0.020 & 0.017 & 0.001 & 0.001 \\
\hline Ln population size & $-0.057^{\wedge}$ & 0.031 & -0.004 & 0.003 \\
\hline \multicolumn{5}{|l|}{ Cross-Level Interactions } \\
\hline \multicolumn{5}{|l|}{ Minority } \\
\hline Intercept (level 1 minority) & $0.169 * * *$ & 0.027 & $-0.013^{* *}$ & 0.005 \\
\hline Minority $\times$ Change in min-to-White employment competition & -0.001 & 0.016 & 0.001 & 0.003 \\
\hline Minority $\times$ Change in $\%$ minorities above the poverty line & $0.007 * *$ & 0.003 & 0.000 & 0.000 \\
\hline Minority $\times$ Change in $\%$ minority population & 0.009 & 0.014 & 0.001 & 0.002 \\
\hline \multicolumn{5}{|l|}{ Number of Observations } \\
\hline Case (Level 1) & \multicolumn{2}{|c|}{121,666} & \multicolumn{2}{|c|}{30,046} \\
\hline County (Level 2) & \multicolumn{2}{|c|}{87} & \multicolumn{2}{|c|}{87} \\
\hline Variance Component & \multirow{2}{*}{\multicolumn{2}{|c|}{$\begin{array}{c}\text { Standard Deviation } \\
0.052^{\wedge}\end{array}$}} & \multirow{2}{*}{\multicolumn{2}{|c|}{$\begin{array}{c}\text { Standard Deviation } \\
0.017^{*}\end{array}$}} \\
\hline Minority & & & & \\
\hline
\end{tabular}

Note: Model controls for all case-level predictors shown in Table 2, but controls are omitted from the table; SE = Standard error. Change minority-to-White employment competition was multiplied by -1 in order to reverse code the variables. ^ $p<0.10$; ${ }^{*} p<0.05$; ${ }^{* *} p<0.01$; $* * * p<0.001$

The main components of the minority threat hypotheses are in the cross-level interactions shown in Table 3. Aligning with minority threat theory, Hypothesis 1 predicts that growing minority populations will have larger minority-White differences at sentencing (i.e., incarceration, sentence length). We find no support for this claim. The cross-level interactions between defendant minority status and change in $\%$ minority population do not reach significance in either the incarceration or sentence length models. Turning to economic threat theory, Hypothesis 2 predicts that counties with growing minority-to-White employment competition (increasing economic threat) will have larger minority-White differences at sentencing. Again, we find no support for this claim as the cross-level interactions testing for these effects are not significant in either model shown in Table 3. As an additional test of economic threat, Hypothesis 3 proposes that counties with increases in the \% of minorities living above the poverty line (increasing economic threat) will have larger minority-White differences at sentencing. We find partial support for this hypothesis. Specifically, the cross-level interaction in the incarceration model shows that minority disadvantage at incarceration increases as the percent of minorities living above the poverty line in a county increases $(b=0.007, p=0.009)$. In other words, minority-White disparity in state prison odds is larger in counties where a growing portion of the minority population is making their way out of poverty. The cross-level interaction between minority and minority poverty rate is insignificant in the sentence length model.

\subsection{Multivariable Analyses: Black and Hispanic Threat}

The above analyses combined Black and Hispanic into a single minority category. However, prior research has identified that racial/ethnic threat may operate differently for Black and Hispanic populations (Feldmeyer et al. 2015). As such, the following models break down racial/ethnic threat propositions separately for Black and Hispanic populations. All case-level control variables are controlled for in subsequent models but not displayed in Tables 4 and 5 due to space consideration. The reader should note, however, that the effects of control variables are nearly identical to the combined minority model. 
Table 4. Hierarchical Regression Model of Incarceration and Sentence Length, Case-Level, County-Level Effects, and Cross-Level Interactions for Black Threat.

\begin{tabular}{|c|c|c|c|c|}
\hline \multirow[b]{2}{*}{ Variable } & \multicolumn{2}{|c|}{ Incarceration } & \multicolumn{2}{|c|}{ Sentence Length } \\
\hline & $b$ & $S E$ & $b$ & $S E$ \\
\hline \multicolumn{5}{|l|}{ Level 1} \\
\hline Black & $0.167^{* * *}$ & 0.027 & $-0.012 *$ & 0.005 \\
\hline Hispanic & $0.284^{* * *}$ & 0.040 & $-0.020^{* *}$ & 0.006 \\
\hline \multicolumn{5}{|l|}{ Level 2: Main Effects } \\
\hline Change in Black-to-White employment competition & -0.006 & 0.005 & $0.001 *$ & 0.001 \\
\hline Change in $\%$ Blacks above the poverty line & 0.002 & 0.001 & -0.000 & 0.000 \\
\hline Change in Black population & -0.019 & 0.057 & 0.007 & 0.006 \\
\hline Ln population size & -0.047 & 0.049 & -0.007 & 0.006 \\
\hline \multicolumn{5}{|l|}{ Level 2: Cross Level Interactions } \\
\hline Black Intercept & $0.167^{* * *}$ & 0.027 & $-0.012 *$ & 0.005 \\
\hline Black $\times$ Change in Black-to-White employment competition & -0.005 & 0.007 & -0.002 & 0.001 \\
\hline Black $\times$ Change in $\%$ Blacks living above the poverty line & $0.004^{\wedge}$ & 0.002 & -0.000 & 0.001 \\
\hline Black $\times$ Change in $\%$ Black population & -0.000 & 0.024 & 0.008 & 0.001 \\
\hline \multicolumn{5}{|l|}{ Number of observations } \\
\hline Case (Level 1) & \multicolumn{2}{|c|}{120,536} & \multicolumn{2}{|c|}{29,857} \\
\hline County (Level 2) & \multicolumn{2}{|c|}{79} & \multicolumn{2}{|c|}{79} \\
\hline Variance Component & \multicolumn{2}{|c|}{ Standard Deviation } & \multicolumn{2}{|c|}{ Standard Deviation } \\
\hline Black (pre-cross-level interaction) & \multicolumn{2}{|c|}{$0.118^{*}$} & \multicolumn{2}{|c|}{$0.020^{* * *}$} \\
\hline Hispanic (pre-cross-level interaction) & \multicolumn{2}{|c|}{0.154} & \multicolumn{2}{|c|}{0.015} \\
\hline
\end{tabular}

Note: Model controls for all case-level predictors shown in Table 2, but controls are omitted from the table; SE = Standard error; Change Black-to-White employment competition was multiplied by -1 in order to reverse code the variables. ${ }^{\wedge} p<0.10 ;{ }^{*} p<0.05 ;{ }^{* *} p<0.01$; $* * * * 0.001$

Table 5. Hierarchical Regression Model of Incarceration and Sentence Length, Case-Level, County-Level Effects, and Cross-Level Interactions for Hispanic Threat.

\begin{tabular}{|c|c|c|c|c|}
\hline \multirow[b]{2}{*}{ Variable } & \multicolumn{2}{|c|}{ Incarceration } & \multicolumn{2}{|c|}{ Sentence Length } \\
\hline & $b$ & $S E$ & $b$ & $S E$ \\
\hline \multicolumn{5}{|l|}{ Level 1} \\
\hline Black & $0.160 * * *$ & 0.027 & $-0.012 *$ & 0.005 \\
\hline Hispanic & $0.296^{* * *}$ & 0.040 & $-0.020 * *$ & 0.006 \\
\hline \multicolumn{5}{|l|}{ Level 2: Main Effects } \\
\hline Change in Hispanic-to-White employment competition & -0.019 & 0.016 & 0.002 & 0.001 \\
\hline Change in \% Hispanics living above the poverty line & -0.001 & 0.002 & -0.000 & 0.000 \\
\hline Change in Hispanic population & 0.012 & 0.019 & 0.001 & 0.001 \\
\hline Ln population size & $-0.053^{\wedge}$ & 0.029 & -0.004 & 0.004 \\
\hline \multicolumn{5}{|l|}{ Level 2: Cross Level Interactions } \\
\hline Hispanic Intercept & - & - & - & - \\
\hline Hispanic $\times$ Change in Hispanic-to-White employ. competition & - & - & - & - \\
\hline Hispanic $\times$ Change in $\%$ Hispanics above the poverty line & - & - & - & - \\
\hline Hispanic $\times$ Change in $\%$ Hispanic population & - & - & - & - \\
\hline \multicolumn{5}{|l|}{ Number of observations } \\
\hline Case (Level 1) & \multicolumn{2}{|c|}{120,507} & \multicolumn{2}{|c|}{30,020} \\
\hline County (Level 2) & \multicolumn{2}{|c|}{85} & \multicolumn{2}{|c|}{85} \\
\hline Variance Component & \multicolumn{2}{|c|}{ Standard Deviation } & \multicolumn{2}{|c|}{ Standard Deviation } \\
\hline Black (pre-cross-level Interaction) & \multicolumn{2}{|c|}{$0.112 *$} & \multicolumn{2}{|c|}{$0.019^{* * *}$} \\
\hline Hispanic (pre-cross-level Interaction) & \multicolumn{2}{|c|}{0.156} & \multicolumn{2}{|c|}{0.014} \\
\hline
\end{tabular}

Note: Model controls for all case-level predictors shown in Table 2, but controls are omitted from the table; SE = Standard error; employ. = employment; Change Hispanic-to-White employment competition was multiplied by -1 in order to reverse code the variables; Cross level interactions are omitted from the table because there was non-significant variation in the effect of Hispanic defendant status across counties. ^ $p<0.10 ;{ }^{*} p<0.05 ;{ }^{* *} p<0.01 ; * * * p<0.001$. 
Table 4 provides the case-level Black and Hispanic effects, county-level main effects, and cross-level interaction estimates for the models assessing Black threat. This model uses all counties which have a non-zero estimate of Blacks in the labor force (79 out of 87). Starting with the case-level estimates, both Blacks and Hispanics are more likely to receive a state prison sentence than similarly situated White defendants. However, both groups receive significantly shorter sentences than similar White defendants. Specifically, Blacks have $18.2 \%$ higher odds of receiving a state prison sentence than Whites but receive about $1.2 \%$ shorter sentences than comparable Whites when sentenced to prison. Similarly, Hispanics have $32.8 \%$ higher odds of receiving a state prison sentence than Whites but receive about $2 \%$ shorter sentences than comparable Whites if sentenced to prison.

In terms of direct county-level effects, we find that counties with rising Black employment rates compared to Whites mete out longer average sentences than counties with shrinking Black employment rates compared to Whites. In other words, the average sentence length is longer in counties when the Black share of employment increases relative to Whites. None of the other direct county-level effects reach significance in Table 4.

Turning to our Black racial threat test (Hypothesis 1), we find no evidence that counties with growing Black populations have larger Black-White differences at either the incarceration or sentence length decision. In terms of Black economic threat, we find no evidence that Black-to-White employment competition contextualizes Black-White differences in sentencing (similar to the overall minority findings and contrary to the expectations of Hypothesis 2). However, we again find partial support for Hypothesis 3, which addresses economic threat based on the change in \% of Blacks living above the poverty line. Although only reaching marginal significance at the incarceration decision, the Black disadvantage in prison sentences (relative to Whites) is greater in counties which experienced rising rates of Blacks living above the poverty line $(b=0.004 ; p=0.071)$, and potentially more Black economic threat. ${ }^{9}$ In other words, Black-White disparity in state prison odds are larger in counties where an increasing cohort of the Black population is emerging from poverty. The cross-level interaction between Black and the \% of Blacks living above the poverty line is not significant in the sentence length model.

Table 5 provides the case-level Black and Hispanic effects, county-level main effects, and cross-level interaction estimates for the models assessing Hispanic threat. This model uses all counties that have a non-zero estimate for Hispanics in the labor force (85 of the 87). Table 5 reveals similar case-level results to the Black models. That is, both Blacks and Hispanics have higher odds of incarceration but receive significantly shorter prison sentences than comparable White defendants. More importantly for the current analysis, the Hispanic effect does not vary significantly across counties. The lack of significant variance in Hispanic-White disparity across both the incarceration and sentence length decision suggest that cross-level interactions between county-level predictors and the Hispanic effect are inappropriate. In other words, Minnesota counties have statistically similar Hispanic-White disparities and there is little variation in the Hispanic effect to explain across counties using our threat variables. The results revealed that no county variables had a statistically significant main effect on incarceration or sentence length. As a result, we do not include cross-level interactions between the Hispanic effect and our Hispanic threat (population or economic) predictors. As such, there appears to be no support for any of the three hypotheses $(1,2$, or 3 ) concerning ethnic or economic threat for Hispanics specifically.

\section{Discussion}

Blalock's (1967) racial/ethnic threat theory has often been used to explain the persistent racial/ethnic disparities throughout the criminal justice system. However, criminal justice research has given limited attention to the potential impact of economic forms of racial/ethnic threat. This oversight is particularly noteworthy given: (a) the historical context of anxieties surrounding racial/ethnic minorities usurping White jobs; (b) the empirical reality that Black and Hispanic jobs have been growing while White jobs have 
been shrinking; and (c) the methodological limitations of past research examining economic threat effects in sentencing (i.e., cross-sectional measures of threat). This study extended research on economic threat in sentencing in a few ways. First, we incorporated a direct test of economic threat alongside the typical racial/ethnic threat test using minority population composition. Second, we used dynamic measures of economic threat, as opposed to static measures, to better operationalize the tenets of Blalock's (1967) propositions. Last, we examined racial/ethnic threat and economic threat in a relatively understudied jurisdiction-Minnesota state courts.

Before discussing the results surrounding the research hypotheses, it is necessary to discuss the case-level minority, Black, and Hispanic effects on sentencing outcomes. The findings revealed that Black and Hispanic defendants were more likely to be sentenced to state prison than Whites, which aligns with prior research (see Feldmeyer et al. 2015; Spohn 2000, 2013; Ulmer 2012). However, Black and Hispanic defendants received significantly shorter average prison sentences than Whites, which contrasts with some prior research (see MacDonald and Donnelly 2019; Feldmeyer et al. 2015; Spohn 2000, 2013). There are a few things that could explain the negative association between minority status and sentence length. First, the in/out and sentence length decisions are conceptualized as distinctwith more consistent effects being detected at the incarceration decision (Johnson 2011; Spohn 2000). Part of the reason for spotty sentence length effects but strong incarceration effects could be that a prison sentence is seen as a means to an end. In other words, once sentenced to prison, the "damage is already done" and the length of that prison sentence matters less (Steffensmeier and Britt 2001; Welch et al. 1988). Thus, judges could be sentencing minorities to prison at a higher rate but either (a) sentencing similarly or (b) correcting for their over-reliance on incarceration for minorities by sentencing them to shorter terms.${ }^{10}$ Second, a large portion of research examining racial/ethnic differences in sentencing outcomes has utilized federal sentencing data (e.g., Holmes and Feldmeyer 2019; Ulmer et al. 2010), while little research has used Minnesota sentencing data. The idea that sentencing effects may differ between federal and state systems is not novel. Spohn (2000) review of the sentencing literature noted that Black and Hispanic disadvantage was more consistent in federal sentencing studies of sentence length (67\% Blacks, 25\% Hispanic) compared to state sentencing studies ( $23 \%$ Blacks, $7 \%$ Hispanics). Minnesota could be distinct, and more research using the Minnesota Sentencing Guideline Commission dataset is needed to better understand the relationship between minority status and sentence length

With the direct effects of minority on sentencing outcomes established, we now turn to our research hypotheses. In terms of the traditional racial/ethnic threat propositions (Hypothesis 1) we find no support for the argument that rising minority, Black, or Hispanic populations, respectively, contextualize minority, Black, or Hispanic, disparity at sentencing. In other words, as minority, Black, or Hispanic populations grew, the effects of defendant race/ethnic status on incarceration and sentence length did not systemically differ.

Similarly, we found no support for economic threat when measured as the minority-toWhite employment competition. In contrast to the predictions of Hypothesis 2, racial/ethnic disparities in sentencing outcomes did not increase (or decrease) as employment competition increased between minorities (or Blacks or Hispanics) and Whites. However, we did find partial support for economic threat as suggested by Hypothesis 3 (but only for incarceration) when examining measures of minority and Black poverty levels. Specifically, counties which saw a growth in minorities living above the poverty line had greater minority-White disparities in incarceration odds than counties which had a declining rate of minorities living above the poverty line. Similarly, counties with growing levels of Blacks, or minorities more generally, living above the poverty line had more Black-White disparity in incarceration odds than counties where Blacks (or minorities more generally) living above the poverty line was declining. We found no evidence that Hispanic poverty contextualized Hispanic-White sentencing disparities.

Taken together, the results identified no support for the standard racial/ethnic threat (i.e., rising minority populations) theory and partial but limited support for economic threat 
theory in Minnesota. Specifically, across three measures of threat, three racial/ethnic groups (minorities, Blacks, and Hispanics), and two outcome measures, only two findings revealed support (both for economic threat) while 16 findings revealed no support for racial/ethnic threat or economic threat theory (see Appendix A for a summary table of the results of each racial/ethnic and economic threat test). In sum, only 2 out of 18 tests of racial/ethnic or economic threat produced significant findings (and one at marginal significance levels). Based on these findings, one would be hard pressed to conclude that racial/ethnic threat as a whole is key driver of sentencing practices in the Minnesota state criminal court system. However, there appear to be some (though notably limited) signs of economic threat, but only at the incarceration decision for minority and, perhaps, Black defendants. The largely null findings of the racial/ethnic threat variables in this study provide some good news for racial/ethnic disparities in the context of sentencing. That is, although minorities face disadvantages at the incarceration decision, contextual level variables-as measured by racial/ethnic threat-do not appear to explain a detectable portion of the racial/ethnic disparities identified. This is encouraging as the larger contextual conditions of an area should not (at least theoretically) influence the sentencing of defendants. It is also worth noting that no evidence was identified suggesting that there was a curvilinear relationship between racial/ethnic or economic threat and sentencing outcomes.

Although it is encouraging that racial/ethnic and economic threat variables had limited influence on racial/ethnic sentencing disparities, racial/ethnic disparities did exist at the case-level, and one measure of economic threat did aggravate these disparities at the incarceration decision. This suggests that, to the degree that racial/ethnic threat does matter in the Minnesota system, it appears to be limited to economic threat for incarceration decisions. A potential explanation for these findings is that racial/ethnic and economic threat work off of the assumption that individuals making the sentencing decision are (a) aware of the social contextual conditions of their jurisdiction and (b) have the ability to consider the social contextual conditions in their decision making process (Britt 2000; Feldmeyer and Cochran 2018). Prior research has suggested that judges and other courtroom actors are aware of the social conditions of their jurisdiction (Britt 2000; Kautt 2002; Ulmer and Kramer 1996). However, other research has identified that judges often have little discretion around sentencing decisions when it comes to more severe sentencing outcomes (Feldmeyer and Cochran 2018; Spohn 2000). Minnesota in particular strongly follows their sentencing guidelines (Frase 2005), which may result in limited discretion for judges at some decision points. Therefore, economic threat conditions may influence judges' decisions to some extent, which may explain the significant findings surrounding change in minority poverty on the incarceration decision, but the limited discretion around some decision points restricts economic threat or racial/ethnic threat from having a consistent influence on the sentence length decision. As such, it is possible that racial/ethnic or economic threat does operate more strongly in Minnesota sentencing in decisions where more discretion is allowed (e.g., the amount to fine a defendant; Feldmeyer and Cochran 2018).

The totality of evidence uncovered partial but limited support for economic threat, which partly aligns with past research. Prior examinations of economic threat had uncovered mixed results (i.e., findings that both supported and refuted economic threat; Carmichael 2005; Jordan and Maroun 2016) or entirely null results (Britt 2000; Wang and Mears 2010). One reason the findings of the current study may partially deviate from prior research is because of the time variant manner in which economic threat was operationalized. Specifically, given Blalock's (1967) depiction of how threat operates, it is likely the rising minority competition in economic resources trigger more punitive treatment of minority groups as opposed to only larger competition.

The findings from this study have several implications for economic and racial/ethnic threat theory in the context of sentencing. First, given that Minnesota uses sentencing guidelines, it is possible that these sentencing guidelines make it difficult for racial/ethnic and economic threat to operate. Specifically, contextual factors may not influence sentencing 
outcomes consistently because, in Minnesota, judges normally make decisions within the suggestions provided by sentencing guidelines. This implication is supported by prior research that has found limited effects of racial/ethnic threat in the federal system-which also utilizes sentencing guidelines (Feldmeyer and Ulmer 2011). Second, while the general null findings surrounding racial/ethnic threat theory are at odds with some prior research that has found support_-albeit mixed support-for racial/ethnic threat (e.g., Feldmeyer et al. 2015; Ulmer and Johnson 2004), it is possible that this departure from prior research stems from our focus on state courts. Limited prior research has examined racial/ethnic threat in state courts (Ulmer and Johnson 2004), and almost no research has examined these relationships in Minnesota. Given this, it is possible that the effect of racial/ethnic threat varies based on the contextual conditions of a given state or jurisdiction in other states. Third, the findings of this study highlight the need for research on racial/ethnic threat to consider all types of threat (i.e., economic, criminal, and political) that Blalock (1967) conceptualized. Had we considered only standard racial/ethnic threat effects here, we would have missed the effect of economic competition on the incarceration decision of minorities. As such, it may no longer be prudent to only examine the standard measure of racial/ethnic threat (i.e., rising minority population) when examining threat theory. Finally, aligning with the findings of Feldmeyer et al. (2015), the results of this study indicate that Black defendants appear to be more impacted by racial/ethnic threat, or economic threat, than Hispanics. This suggests that when considering racial/ethnic threat theory (and its various forms) it is wise to separate race and ethnicity as opposed to examining threat more generally.

Overall, the findings from the current study do not explain a large portion of between county variation in racial/ethnic disparities discovered in Minnesota State Courts. This highlights the pressing need for more research in Minnesota to uncover why these disparities exist. From a practical standpoint, it may be prudent for Minnesota state courts to conduct research that aims to identify mechanisms-other than contextual conditions (e.g., judicial perceptions) — that may be leading to racial/ethnic disparities in sentencing outcomes. From a racial/ethnic threat standpoint, more research is needed to identify whether threat operates in any mechanism in Minnesota courts. Specifically, future research needs to take careful steps to (1) examine all aspects of threat theory (i.e., political and criminal threat), (2) produce theoretically informed measures of each aspect of the theory (i.e., measures of threat that capture changing levels of political or crime threat overtime), and (3) focus on the moderating effects of racial/ethnic threat theory on sentencing outcomes, as opposed to the direct effects. If consistent and concrete evidence of racial/ethnic threat is uncovered in Minnesota, then proactive practical implications can be formed in order to address the disparities occurring in Minnesota that result from racial/ethnic threat. If consistent evidence of threat is not found in Minnesota-as is largely suggested by the findings of the current study-then researchers can focus their attention on other reasons racial/ethnic disparities may be persisting.

Although more research is needed to uncover the driving factors behind the racial/ethnic disparities identified in the incarceration decision, the results of the current study highlight two practical implications. First, it may be valuable for courts to inform its actors on the potential influence of economic threat on racial/ethnic disparities in sentencing outcomes. This may help minimize the chance that threat factors influence outcomes. Second, as touched on above, the fact that the majority of threat factors did not contribute to racial/ethnic disparities could suggest that the Minnesota sentencing guidelines reduce the ability of racial/ethnic and economic threat variables to influence sentencing decisions. While the results of our study do not provide clear evidence as to how much the sentencing guidelines are responsible for the limited effect of threat variables, it may be a positive sign that under this guideline system the influence of racial/ethnic and economic threat is generally limited. 


\section{Limitations}

The current study provided a dynamic examination of economic and racial/ethnic threat in Minnesota sentencing decisions. The results revealed some, but inconsistent, support for economic threat. Although this study provided a valuable extension to research, there are a few noteworthy limitations. First, the social and economic contexts of Minnesota must be considered when interpreting these results. According to the U.S. Census, racial/ethnic minorities in Minnesota are largely concentrated in a handful of counties. As such, numerous counties within Minnesota are racially/ethnically homogenous. Furthermore, some evidence suggests that racial/ethnic minorities (especially Blacks) face greater disadvantages in income and education in Minnesota compared to other states (Morris 2020). These factors-Minnesota being largely racially/ethnically homogenous in most counites and minorities facing relative disadvantage in education and income-may indicate that minorities pose little racial/ethnic or economic threat throughout the state. This lack of threat may reduce the ability of threat variables to have an influence on variation in sentencing outcomes. However, one could also argue that because the minority population is small in some counites and minorities face economic disadvantage, court actors may be more aware of increases in minority threat as it may be easier to detect then in areas with larger minority populations, where minorities have an established economic presence. Future research should test the effect of economic and racial/ethnic threat on sentencing outcomes in states with differing minority presence to determine whether the theory may operate differently in states with varying levels of minority presence and economic competition. By doing so, policymakers, legislators, and researchers will gain a better understanding of how, when, and in what ways economic and racial/ethnic threat operates.

Second, the analyses were limited by omitting some important case-level characteristics, specifically education and employment. While the MSGC dataset did not allow us to control for these variables, prior research suggests that these measures have a significant (albeit small in magnitude) influence on sentencing decisions after controlling for a battery of legal and extralegal factors (e.g., race, gender, and age; Franklin et al. 2017; Steffensmeier et al. 1998). Third, the MSGC dataset lacks specific detail as to whether White and Hispanic race/ethnicity defendants are parsed out by non-Hispanic Whites and Hispanics. Although the "race" variable in the MSGC dataset treats White, Black, and Hispanic defendants as mutually exclusive nominal groupings, we cannot be sure that these categories are truly mutually exclusive.

\section{Conclusions}

Understanding the persistent racial/ethnic disparities in the criminal justice system has been a consistent focus of scholars for many decades. Racial/ethnic threat has been a popular theoretical framework used to understand these disparities. However, the economic threat component of racial/ethnic threat has been vastly overlooked. The current study expansively inspected economic threat in the context of sentencing. Utilizing time variant measures of economic threat, the results suggested that economic threat may explain some, but limited, variation in sentencing outcomes in Minnesota for minority defendants, particularly Black defendants. Nevertheless, research should continue to explore how various aspects of racial/ethnic threat (i.e., political and criminal threat) may influence sentencing outcomes for minority defendants using time variant measures of said threat.

Author Contributions: Conceptualization, C.D. and B.H.; methodology, C.D., B.H. and B.F.; software, B.H. and C.D.; formal analysis, B.H. and C.D.; investigation, C.D., B.H. and B.F.; resources, C.D., B.H. and B.F.; data curation, C.D. and B.H.; writing-original draft preparation, C.D.; writing-review and editing, C.D., B.H. and B.F.; visualization, C.D., B.H. and B.F.; project administration, C.D., B.H. and B.F.; All authors have read and agreed to the published version of the manuscript.

Funding: This research received no external funding.

Informed Consent Statement: Not applicable. 
Data Availability Statement: Case-level data can be requested from the Minnesota Sentencing Guidelines Commission website https:/ / mn.gov/sentencing-guidelines/contact/data-requests.jsp (accessed on 31 May 2021). County-level data is available from the United States Census Bureau website https: / / www.census.gov (accessed on 31 May 2021).

Conflicts of Interest: The authors declare no conflict of interest.

Appendix A. Support for Theoretical Predictions of Racial/Ethnic \& Economic Threat on Sentencing Outcomes

\begin{tabular}{|c|c|c|}
\hline \multirow[b]{2}{*}{ Theoretical Predictions } & \multicolumn{2}{|c|}{ Supported } \\
\hline & Prison & Sentence Length \\
\hline \multicolumn{3}{|l|}{ Minority Threat } \\
\hline Counties with growing minority populations will have larger minority-White differences & No & No \\
\hline $\begin{array}{l}\text { Counties with growing minority-to-White employment competition will have larger } \\
\text { minority-White differences }\end{array}$ & No & No \\
\hline $\begin{array}{l}\text { Counties with an increasing } \% \text { of minorities above the poverty line will have larger } \\
\text { minority-White differences }\end{array}$ & Yes ** & No \\
\hline \multicolumn{3}{|l|}{ Black Threat } \\
\hline Counties with growing Black populations will have larger Black-White differences & No & No \\
\hline $\begin{array}{l}\text { Counties with growing Black-to-White employment competition will have larger } \\
\text { Black-White differences }\end{array}$ & No & No \\
\hline $\begin{array}{l}\text { Counties with an increasing } \% \text { of Blacks above the poverty line will have larger } \\
\text { Black-White differences }\end{array}$ & Yes^ & No \\
\hline \multicolumn{3}{|l|}{ Hispanic Threat } \\
\hline Counties with growing Hispanic populations will have larger Hispanic-White differences & No & No \\
\hline $\begin{array}{l}\text { Counties with growing Hispanic-to-White employment competition will have larger } \\
\text { Hispanic-White differences }\end{array}$ & No & No \\
\hline $\begin{array}{l}\text { Counties with an increasing } \% \text { of Hispanics above the poverty line will have larger } \\
\text { Hispanic-White differences }\end{array}$ & No & No \\
\hline
\end{tabular}

Note: ^ $p<0.10 ;{ }^{* *} p<0.01$.

\section{Notes}

1 Carmichael (2005) found that larger racial disparity in income was found as a significant predictor of more jail use. The author interpreted this finding as in support of economic threat by stating that because the resources of the majority greatly exceed those of the minority group, the majority group can more easily deploy resources to control the minority group. While this finding is notable, it differs from traditional interpretation of economic threat, which suggest that areas with more economic competition would be expected to have greater disparity in sentencing outcomes (Blalock 1967).

2 Ancillary analyses were conducted including American Indian, Asian, and Other defendants in our measure of minority defendants. The results revealed no substantive or significant differences with these defendants included. In order to stay consistent with Blalock's (1967) theory and prior research, only models and analyses including Black and Hispanic defendants are presented and discussed.

3 We coded 120 cases as receiving a state prison sentence althought they included no prison sentence length. Supplemental models with these 120 cases in the analyses were estimated, but they presented substantial bias to the sentence length models. Specifically, in postregression sentence length diagnostics all of the 120 cases had standardized residuals of less than -10 .

4 It is common practice in prior sentencing research to top-code sentence length variables at around 470 months-the approximation of a life sentence (Kitchens 2010). In the Minnesota Sentencing Guidelines dataset, the longest sentence given was approximately 480 months. Given the relatively close proximity to 470 months of the longest sentence in the study sample, we leave the variable coded as is as opposed to top-coding.

5 The variable was coded in this manner (rather than White-to-minority employment competition) because coding the variable as White-to-minority employment competition resulted in some counties being counted as missing because they had zero estimated unemployed minorities (but a non-zero estimate of minorities in the labor force).

6 Notably, we explored other county level control variables (e.g., caseload size, single headed households) and the results demonstrated no significant influence of these variables on sentencing outcomes.

7 An important consideration when estimating predictors effect on sentence length is sample selection bias as the sentence length model omits cases from the incarceration decision. In order to account for this concern, we conducted a Heckman's correction for selection bias. However, we found that the mills ratio was highly correlated with our legal variables. Therefore, we did not include the mills ratio in our final models (Bushway et al. 2007). 
8 Counties were removed from the Black models when there were zero estimated Blacks in the labor force in 2000 or 2010 and removed from the Hispanic models when there were zero estimated Hispanics in the labor force in 2000 or 2010.

9 A supplementary analysis was conducted where the models from Table 4 were replicated but with the combined minority measures of economic and racial/ethnic threat at level 2. The results revealed a statistically significant relationship between Black defendant status and \% change in minorities above the poverty line. Similar to the findings between Black defendant status and change in Black poverty rate, the Black disadvantage at incarceration (relative to Whites), is greater in counties that experienced rising rates of minorities living above the poverty line $(b=0.009 ; p=0.007)$ between 2000 and 2010, and potentially more minority economic competition or threat.

10 In order to partially test this explanation, we examined the difference in average sentence length received by minorities against their expected sentence length (identified by the average presumptive sentence for minorities) and compared it to the difference in average sentence length received by Whites against their expected sentence length. The results indicated that minorities are sentenced to an average of about 6.5 months less in prison then their presumptive recommended sentences, while Whites are sentenced to about 3.5 months less in prison then their presumptive recommended sentences. This potentially provides preliminary evidence that judges could be correcting for an overreliance on incarceration for minorities by reducing minority sentence lengths more than Whites—-when compared to the presumptive sentence provided by the guideline.

\section{References}

Albonetti, Celesta A. 1991. An integration of theories to explain judicial discretion. Social Problems 38: 247-66. [CrossRef]

Baumer, Eric P. 2013. Reassessing and redirecting research on race and sentencing. Justice Quarterly 30: 231-61. [CrossRef]

Beck, Allen J., and Alfred Blumstein. 2018. Racial disproportionality in U.S. state prisons: Accounting for the effects of racial and ethnic differences in criminal involvement, arrests, sentencing, and time served. Journal of Quantitative Criminology 34: 853-83. [CrossRef]

Behrens, Angela, Christopher Uggen, and Jeff Manza. 2003. Ballot manipulation and the "menace of negro domination": Racial threat and felon disenfranchisement in the United States, 1850-2002. American Journal of Sociology 190: 559-605. [CrossRef]

Bibas, Stephanos. 2015. Designing plea bargaining from the ground up: Accuracy and fairness without trials as backstops. William and Mary Law Review 57: 1055-81.

Blalock, Hubert M., Jr. 1967. Toward a Theory of Minority-Group Relations. New York: Wiley.

Blauner, Bob. 1972. Racial Oppression in America. New York: Harper and Row.

Blumer, Herbert. 1958. Race prejudice as a sense of group position. Sociological Perspectives 1: 3-7.

Britt, Chester L. 2000. Social context and racial disparities in punishment decisions. Justice Quarterly 17: 707-32. [CrossRef]

Bushway, Shawn D., and Anne Morrison Piehl. 2001. Judging judicial discretion: Legal factors and racial discrimination in sentencing. Law and Society Review 35: 733-64. [CrossRef]

Bushway, Shawn, Brian D. Johnson, and Lee Ann Slocum. 2007. Is the magic still there? The use of the Heckman two-step correction for selection bias in criminology. Journal of Quantitative Criminology 23: 151-78. [CrossRef]

Caravelis, Cyndy, Ted Chiricos, and William Bales. 2011. Static and dynamic indicators of minority threat in sentencing outcomes: A multi-level analysis. Journal of Quantitative Criminology 27: 405-25. [CrossRef]

Caravelis, Cyndy, Ted Chiricos, and William Bales. 2013. Race, ethnicity, threat, and the designation of career offenders. Justice Quarterly 30: 869-94. [CrossRef]

Carmichael, Jason T. 2005. The determinants of jail admission rates across large U.S. cities: An analysis of racial and ethnic threat theory. Social Science Research 34: 538-69. [CrossRef]

Carmichael, Jason T. 2010. Sentencing disparities for juvenile offenders sentenced to adult prisons: An individual and contextual analysis. Journal of Criminal Justice 38: 747-57. [CrossRef]

Chambliss, William. 1976. The state and criminal law. In Whose Law? What Order? A Conflict Approach to Criminology. Edited by William Chambliss and Milton Mankoff. New York: Wiley, pp. 66-106.

Chamlin, Mitchell B. 1989. A macro social analysis of change in police force size, 1972-1982—controlling for static and dynamic influences. Sociological Quarterly 30: 615-24. [CrossRef]

Chiricos, Ted, Sarah Eschholz, and Marc Gertz. 1997. Crime, news and fear of crime: Toward an identification of audience effects. Social Problems 44: 342-357. [CrossRef]

Chiricos, Ted, Kathy Padgett, Jake Bratton, Justin T. Pickett, and Marc Gertz. 2012. Racial threat and opposition to the re-enfranchisement of ex-felons. International Journal of Criminology and Sociology 1: 13-28. [CrossRef]

Chiricos, Ted, Ranee McEntire, and Marc Gertz. 2001. Perceived racial and ethnic composition of neighborhood and perceived risk of crime. Social Problems 48: 322-40. [CrossRef]

Chomsky, Aviva. 2018. They Take Our Jobs! and 20 Other Myths about Immigration. Boston: Beacon Press.

D'Alessio, Stewart J., Lisa Stolzenberg, and David Eitle. 2002. The effect of racial threat on interracial and intraracial crimes. Social Science Research 31: 392-408. [CrossRef]

Doerner, Jill K., and Stephen Demuth. 2010. The independent and joint effects of race/ethnicity, gender, and age on sentencing outcomes in US federal courts. Justice Quarterly 27: 1-27. [CrossRef]

Doerner, Jill K., and Stephen Demuth. 2014. Gender and sentencing in the federal courts: Are women treated more leniently? Criminal Justice Policy Review 25: 242-69. [CrossRef] 
Economic Cycle Research Institute. 2016. U.S. Cyclical Eutlook Essentials. Economic Cycle Research Institute. Available online: https://ecri-prod.s3.amazonaws.com/downloads/1611USCO_Essentials_EXCERPT.pdf (accessed on 15 December 2020).

Eitle, David, and John Taylor. 2008. Are Hispanics the new "threat"? Minority group threat and fear of crime in Miami-Date county. Social Science Research 37: 1102-15. [CrossRef] [PubMed]

Eitle, David, Stewart J. D'Alessio, and Lisa Stolzenberg. 2002. Racial threat and social control: A test of the political, economic, and threat of black crime hypotheses. Social Forces 81: 557-76. [CrossRef]

Federal Bureau of Investigation. 2018. Crime in the United States, 2018: Table 43. Washington, D.C.: Department of Justice, Federal Bureau of Investigation.

Feldmeyer, Ben, and Joshua Cochran. 2018. Racial threat and social control: A review and conceptual framework for advancing racial threat theory. In Building a Black Criminology: Race, Theory, and Crime. Edited by James D. Unnever, Shaun L. Gabbidon and Cecilia Chouhy. London: Routledge, pp. 283-316.

Feldmeyer, Ben, and Jeffery T. Ulmer. 2011. Racial/ethnic threat and federal sentencing. Journal of Research in Crime and Delinquency 48: 238-70. [CrossRef]

Feldmeyer, Ben, Patricia Y. Warren, Sonja E. Siennick, and Malisa Neptune. 2015. Racial, ethnic, and immigrant threat: Is there a new criminal threat on state sentencing? Journal of Research in Crime and Delinquency 52: 62-92. [CrossRef]

Franklin, Travis W., and Tri Keah S. Henry. 2020. Racial disparities in federal sentencing outcomes: Clarifying the role of criminal history. Crime E Delinquency 66: 3-32.

Franklin, Travis W., Layne Dittmann, and Tri Keah S. Henry. 2017. Extralegal disparity in the application of intermediate sanctions: An analysis of US district courts. Crime E Delinquency 63: 839-74.

Frase, Richard S. 2005. Sentencing guidelines in Minnesota, 1978-2003. Crime and Justice 32: 131-219. [CrossRef]

Fredriksson, Klara. 2017. One Felon, no Vote: The Role of Racial Threat in Felon Disenfranchisement Laws across the United States. Lund: Lund University, Department of Political Science.

Hoban, Brennan. 2017. Do Immigrants "Steal" Jobs from American Workers? Brooking Institute. Available online: https://www.brookings. edu/blog/brookings-now/2017/08/24/do-immigrants-steal-jobs-from-american-workers/ (accessed on 10 January 2021).

Holmes, Bryan, and Ben Feldmeyer. 2019. Reassessing the influence of criminal history in federal criminal courts. Justice Quarterly 36: 1206-28. [CrossRef]

Holmes, Bryan, and Christopher D'Amato. 2020. Judicial and prosecutorial decision making: Assessing the effects of race, gender, and age on federal downward sentencing departures, 2013-2016. Journal of Crime and Justice 43: 449-66. [CrossRef]

Jacobs, David, and Jason T. Carmichael. 2001. The politics of punishment across time and space: A pooled time-series analysis of imprisonment rates. Social Forces 80: 61-89. [CrossRef]

Jacobs, David, Jason T. Carmichael, and Stephanie L. Kent. 2005. Vigilantism, current racial threat, and death sentences. American Sociological Review 70: 656-77. [CrossRef]

Johnson, Brian D. 2005. Contextual disparities in guidelines departures: Courtroom social contexts, guidelines compliance, and extralegal disparities in criminal sentencing. Criminology 43: 761-96. [CrossRef]

Johnson, Brian D. 2011. Sentencing. In Oxford Handbook of Crime and Criminal Justice. Edited by Michael Tonry. Oxford: Oxford University Press, pp. 696-729.

Johnson, Brian D., Jeffery T. Ulmer, and John H. Kramer. 2008. The social context of guidelines circumvention: The case of federal district courts. Criminology 46: 737-83. [CrossRef]

Jordan, Kareem L., and Rimonda Maroun. 2016. Minority threat and criminal sentencing: Examining juveniles in the adult criminal justice system. Journal of Crime and Justice 39: 41-54. [CrossRef]

Kautt, Paula M. 2002. Location, location, location: Interdistrict and intercircuit variation in sentencing outcomes for federal drugtrafficking offenses. Justice Quarterly 19: 633-69. [CrossRef]

Kent, Stephanie L., and David Jacobs. 2004. Social divisions and coercive control in advanced societies: Law enforcement strength in eleven nations from 1975 to 1994. Social Problems 51: 343-61. [CrossRef]

Kitchens, Christine. 2010. Federal Sentencing Data and Analysis Issues. Washington, D.C.: Office of Research and Data United States Sentencing Commission.

Light, Michael T., Michael Massoglia, and Ryan D. King. 2014. Citizenship and punishment: The salience of national membership in U.S. criminal courts. American Sociological Review 79: 825-47. [CrossRef]

Liska, Allen E. 1992. Social Threat and Social Control. Albany: State University of New York Press.

Liska, Allen E., and Mitchell B. Chamlin. 1984. Social structure and crime control among macro-social units. American Journal of Sociology 90: 383-95. [CrossRef]

MacDonald, John M., and Ellen A. Donnelly. 2019. Evaluating the role of race in sentencing: A entropy weighting analysis. Justice Quarterly 36: 656-81. [CrossRef]

Mears, Daniel P., Christina Mancini, and Eric A. Stewart. 2009. Whites' concern about crime: The effects of interracial contact. Journal of Research in Crime and Delinquency 46: 524-52. [CrossRef]

Mears, Daniel P., Joshua C. Cochran, and Andrea M. Lindsey. 2016. Offending and racial and ethnic disparities in criminal justice: A conceptual framework for guiding theory and research and informing policy. Journal of Contemporary Criminal Justice 32: 78-103. [CrossRef] 
Mears, Daniel P., Justin Pickett, Kristin Golden, Ted Chiricos, and Marc Gertz. 2013. The effect of interracial contact on whites' perceptions of victimization risk and black criminality. Journal of Research in Crime and Delinquency 50: 272-99. [CrossRef]

Minnesota Sentencing Guidelines Commission. 2019. 2019 Sentencing Practices: Annual Summary Statistics for Felony Cases Sentenced in 2019. Available online: https:// mn.gov/sentencing-guidelines/assets/2019MSGCAnnualSummaryStatistics_tcm30-457007.pdf (accessed on 21 September 2020).

Morris, Kathy. 2020. Racial disparity in America: The 10 worst states for Black Americans. Zippia: The Career Expert. Available online: https:/ / www.zippia.com/advice/racial-disparity-worst-states/ (accessed on 17 May 2021).

Pfaff, John. 2017. Locked in: The True Causes of Mass Incarceration and How to Achieve Real Reform. New York: Basic Books.

Pickett, Justin T., Ted Chiricos, Kristin M. Golden, and Marc Gertz. 2012. Reconsidering the relationship between perceived neighborhood racial composition and whites' perception of victimization risk: Do racial stereotypes matter? Criminology 50: 145-86. [CrossRef]

Raudenbush, Stephen W., and Anthony S. Bryk. 2002. Hierarchical Linear Models: Applications and Data Analysis Methods, 2nd ed. New York: Sage Publications.

Sampson, Robert J., and John H. Laub. 1993. Structural variations in juvenile court processing: Inequality, the underclass, and social control. Law and Society Review 27: 285-311. [CrossRef]

Spohn, Cassie. 2000. Thirty years of sentencing reform: The quest for a racially neutral sentencing process. Criminal Justice 3: 427-61.

Spohn, Cassie. 2013. The effects of offender's race, ethnicity, and sex on federal sentencing outcomes in the guidelines era. Law $\mathcal{E}$ Contemporary Problems 76: 75-104.

Steffensmeier, Darrell, and Chester L. Britt. 2001. Judges' race and judicial decision making: Do black judges sentence differently? Social Science Quarterly 82: 749-64. [CrossRef]

Steffensmeier, Darrell, Jeffery Ulmer, and John Kramer. 1998. The interaction of race, gender, and age in criminal sentencing: The punishment cost of being young, black, and male. Criminology 36: 763-98. [CrossRef]

Steffensmeier, Darrell, Noah Painter-Davis, and Jeffery Ulmer. 2017. Intersectionality of race, ethnicity, gender, and age on criminal punishment. Sociological Perspectives 60: 810-33. [CrossRef]

Stolzenberg, Lisa, Stewart J. D'Alesso, and David Eitle. 2004. A multilevel test of racial threat theory. Criminology 42: 673-98. [CrossRef]

Stuntz, William J. 2011. The Collapse of American Criminal Justice. Cambridge: Harvard University Press.

The Sentencing Project. 2018. Report of the Sentencing Project to the United Nations Special Rapporteur on Contemporary Forms of Racism, Racial Discrimination, Xenophobia, and Related Intolerance: Regarding Racial Disparities in the United States Criminal Justice System. The Sentencing Project, Research and Advocacy for Reform. Available online: https: / www.sentencingproject.org/publications/unreport-on-racial-disparities / / (accessed on 2 October 2020).

Turk, Austin T. 1969. Criminality and Legal Order. Chicago: Rand McNally.

Uggen, Christopher, and Jeff Manza. 2002. Democratic contradiction? Political consequences of felon disenfranchisement in the United States. American Sociological Review 67: 777-803. [CrossRef]

Ulmer, Jeffery T. 2000. The rules have changed-so proceed with caution: A comment on Engen and Gainey's method for modeling sentencing outcomes under guidelines. Criminology 38: 1231-43. [CrossRef]

Ulmer, Jeffery T. 2012. Recent developments and new directions in sentencing research. Justice Quarterly 29: 1-40. [CrossRef]

Ulmer, Jeffery T., and Brian Johnson. 2004. Sentencing in context: A multilevel analysis. Criminology 42: 137-78. [CrossRef]

Ulmer, Jeffery T., and Brandy R. Parker. 2020. Federal Sentencing of Hispanic Defendants in Changing Immigrant Destinations. Justice Quarterly 37: 541-70. [CrossRef]

Ulmer, Jeffery T., and John H. Kramer. 1996. Court communities under sentencing guidelines: Dilemmas of formal rationality and sentencing disparity. Criminology 34: 383-408. [CrossRef]

Ulmer, Jeffery T., and Mindy S. Bradley. 2006. Variation in trial penalties among serious violent offenses. Criminology 44: 631-70. [CrossRef]

Ulmer, Jeffery T., James Eisenstein, and Brian D. Johnson. 2010. Trial penalties in federal sentencing: Extra guidelines factors and district variation. Justice Quarterly 27: 560-92. [CrossRef]

Wang, Xia, and Daniel P. Mears. 2010. A multilevel test of minority threat effects on sentencing. Journal of Quantitative Criminology 26: 191-215. [CrossRef]

Weidner, Robert R., Richard S. Frase, and Jennifer S. Schultz. 2005. The impact of contextual factors on the decision to imprison in large urban jurisdictions: A multilevel analysis. Crime $\mathcal{E}$ Delinquency 51: 400-24.

Welch, Susan, Michael Combs, and John Gruhl. 1988. Do black judges make a difference? American Journal of Political Science 32: 126-36. [CrossRef]

Zatz, Marjorie S. 1987. The changing forms of racial/ethnic biases in sentencing. Journal of Research in Crime and Delinquency $24:$ 69-92. [CrossRef] 